patients (16.09\%) and 4 cases among 33 staff (12.12\%) who were suspected cases. Furthermore, 7 confirmed and suspected hemodialysis patients died between February 4 and February 13, 2020. ${ }^{5}$ Also, 5 confirmed patients and no healthcare workers or facility workers were infected between February 14 and March 1, 2020. Collectively, these strategies can effectively minimize clusters of infection while providing timely treatment for hemodialysis patients.

\section{Acknowledgments.}

Financial support. No financial support was provided relevant to this article.

Conflicts of interest. All authors report no conflicts of interest relevant to this article.

\section{References}

1. The National Health Commission of PRC. Guideline for diagnosis and treatment of novel coronavirus disease (version 6). February 18, 2020. http://www. nhc.gov.cn/yzygj/s7653p/202002/8334a8326dd94d329df351d7da8aefc2.shtml. Updated February 18, 2020. Accessed February 19, 2020.

2. Guideline for diagnosis and treatment of novel coronavirus disease (version 7). The National Health Commission of PRC website. http://en.nhc.gov.cn/202003/29/c_78469.htm. Updated March 29, 2020. Accessed April 22, 2020.

3. Naicker S, Yang CW, Hwang SJ, Liu BC, Chen JH, Jha V. The novel coronavirus 2019 epidemic and kidneys. Kidney Int 2020. doi: 10.1016/j.kint.2020. 03.001 .

4. Interim additional guidance for infection prevention and control recommendations for patients with suspected or confirmed COVID-19 in outpatient hemodialysis facilities. Centers for Disease Control and Prevention website. https://www.cdc.gov/coronavirus/2019-ncov/healthcare-facilities/dialysis.html. Updates April 12, 2020. Accessed April 22, 2020.

5. Ma Y. 2019 novel coronavirus disease in hemodialysis (HD) patients: report from one HD center in Wuhan, China. medRxiv 2020. doi: 10.1101/2020.02. 24.20027201.

\title{
COVID-19 in the endoscopy ward: A potential risk for gastroenterologists
}

\author{
Ahmad Hormati MD¹, Mohammad Hadi Karbalaie Niya $\mathrm{PhD}^{2}$, Mohammadreza Ghadir MD ${ }^{1}$, Kamran Bagheri Lankarani MD \\ Hossein Ajdarkosh MD², Fahimeh Safarnezhad Tameshkel PhD candidate ${ }^{2}$ and Farhad Zamani MD ${ }^{2}$ (1) \\ ${ }^{1}$ Gastroenterology and Hepatology Disease Research Center, Qom University of Medical Sciences, Qom, Iran, ${ }^{2}$ Gastrointestinal and Liver Diseases Research \\ Center, Iran University of Medical Sciences, Tehran, Iran and ${ }^{3}$ Health Policy Research Center, Shiraz University of Medical Sciences, Fars, Iran
}

To the Editor-COVID-19, an emerging coronavirus disease, is major health problem. As of April 15, 2020, it involved 2,035,299 cases globally, of whom 130,712 died. ${ }^{1,2}$ Coronaviruses comprise a range of positive-sense RNA viruses including several zoonotic viruses. Severe acute respiratory coronavirus type 2 (SARS-CoV-2) has become serious and devastating threat worldwide; it spreads quickly among humans via 2 major routes: respiratory and fecal-oral. Contaminated droplets are the major source of the virus transmission, and the disease initially occurs in the respiratory tract. ${ }^{3}$ Human-to-human transmission by direct contact at $<1 \mathrm{~m}$ is the most effective way to transfer an infective amount of the virus, and this type of contact occurs frequently in medical centers during routine practice. In addition, the stability of the virus on solid surfaces is high, which puts the medical center setting at high risk for viral contamination. ${ }^{4}$ Thus, medical centers are critical areas for disease control. Unrecognized COVID-19 cases referred for routine endoscopic practice are a probable source of viral contamination of facilities. Endoscopic procedures can facilitate airborne transmission as well as contamination of surfaces. Medical personnel are at risk for disease dissemination by various routes. ${ }^{5}$ Iran, a Middle Eastern country, has a high rate of COVID-19. In Iran, 76,389 confirmed cases and 4,777 deaths have been reported, and Iran ranks first among Middle Eastern countries and eighth in the world for COVID-19 prevalence. ${ }^{1,2}$ Here,

Author for correspondence: Professor Farhad Zamani, E-mail: zamani.f@iums.ac.ir Cite this article: Hormati A, et al. (2020). COVID-19 in the endoscopy ward: A potential risk for gastroenterologists. Infection Control \& Hospital Epidemiology, 41: 1242-1243, https://doi.org/10.1017/ice.2020.160 we report the COVID-19 prevalence in Iranian endoscopic wards among gastroenterologists.

All gastroenterologists who are on call and who routinely worked in referral hospitals are at risk of viral infection, and unusual presentation of COVID-19 may expose them unexpectedly to the disease. ${ }^{6,7}$ We surveyed these specialists to evaluate the prevalence of COVID-19 and hospitalization using a standard protocol for COVID-19 diagnosis. We distributed a questionnaire to all gastrointestinal wards in Iran, and we received responses from $\sim 480$ gastroenterologists by March 26,2020 . Our data analysis revealed that 51 of these gastroenterologists (10.6\%) had COVID-19 symptoms that had been confirmed by a laboratory test. Among these cases, $60 \%$ had moderate disease, $30 \%$ had mild disease, and $10 \%$ had severe disease. Furthermore, patients with gastrointestinal symptoms may represent a source of underdiagnosed COVID-19 cases because they do not present with classic symptoms of the disease such as fever and respiratory signs. ${ }^{6,7}$

Personal protection equipment (PPE) is crucial for preventing exposure to the virus. Various protocols have been recommended for PPE for clinicians as well as patients. Endoscopy patients should wear a special gown, mask, and gloves based on their classification as intermediate- or high-risk patients. ${ }^{5}$ Endoscopy personnel should use standard protective clothing and should maintain a reasonable distance of contact with all patients, especially suspicious cases. The minimal personal protective equipment (PPE) recommended elsewhere should be used, especially by at-risk individuals such as gastroenterologists (Fig. 1). ${ }^{5}$

In conclusion, gastroenterologists, as on-call experts, are at higher risk for COVID-19 via the fecal-oral route as well as the

(c) 2020 by The Society for Healthcare Epidemiology of America. All rights reserved. This is an Open Access article, distributed under the terms of the Creative Commons Attribution licence (http://creativecommons.org/licenses/by/4.0/), which permits unrestricted re-use, distribution, and reproduction in any medium, provided the original work is properly cited. 


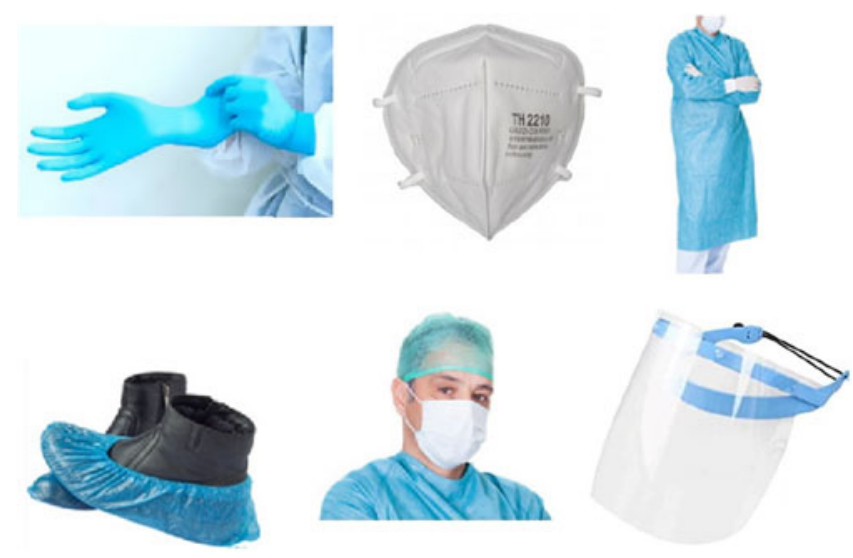

Fig. 1. Personal protection equipment (PPE) should used by medical personnel in the endoscopy ward.

respiratory route during routine practice. Isolation of all patients and strict use of PPE should be observed to reduce the disease burden. In the context of the COVID-19 pandemic, unidentified cases should be detected by implementing more precaution guidelines. For gastrointestinal specialists in endoscopy wards, we highly recommend that they wear at least surgical mask and glasses during clinical visits and that they wear a N95 mask, glasses, a face shield, and latex gloves (not vinyl gloves) during endoscopic procedures.
Acknowledgments. Authors are thankful for kind assistance of Iranian Association of Gastroenterology and Hepatology.

Financial support. No financial support was provided relevant to this article.

Conflicts of interest. All authors report no conflicts of interest relevant to this article.

\section{References}

1. Coronavirus disease (COVID-2019) situation reports. World Health Organization website. https://www.whoint/emergencies/diseases/novel-coronavirus2019/situation-reports. Published 2020. Accessed April 22, 2020.

2. COVID-19 coronavirus pandemic: April 15, 2020. Worldometer website. https://wwwworldometersinfo/coronavirus/?utm_campaign=homeAdvegas1? \%20. Published April 15, 2020. Accessed April 22, 2020.

3. Tong Z-D, Tang A, Li K, et al. Potential presymptomatic transmission of SARS-CoV-2, Zhejiang Province, China, 2020. Emerg Infect Dis 2020;26: $1052-1054$.

4. van Doremalen N, Bushmaker T, Morris DH, et al. Aerosol and surface stability of SARS-CoV-2 as compared with SARS-CoV-1. N Engl J Med 2020;382:1564-1567.

5. Repici A, Maselli R, Colombo M, et al. Coronavirus (COVID-19) outbreak: what the department of endoscopy should know. Gastroint Endosc 2020 Mar 14 [Epub ahead of print]. doi: 10.1016/j.gie.2020.03.019.

6. Hormati A, Ghadir MR, Zamani F, Khodadadi J, Afifian M, Ahmadpour S. The preventive strategies of GI physicians during the COVID-19 pandemic. N Microbes N Infect 2020. doi: 10.1016/j.nmni.2020.100676.

7. Hormati A, Shahhamzeh A, Afifian M, Khodadust F, Ahmadpour S. Can COVID-19 present unusual GI symptoms? J Microbiol Immunol Infect 2020 Mar 21 [Epub ahead of print]. doi: 10.1016/j.jmii.2020.03.020.

\title{
Knowledge of coronavirus disease 2019 (COVID-19) by medical personnel in a rural area of Thailand
}

\author{
Patthamaporn Apaijitt ${ }^{1}$ and Viroj Wiwanitkit ${ }^{2,3}$ \\ ${ }^{1}$ Nangron Hospital, Buriram, Thailand, ${ }^{2}$ Dr DY Patil University, Pune, India and ${ }^{3}$ Hainan Medical University, Haikou, China
}

To the Editor - Coronavirus disease (COVID-19) is a new respiratory infection that is a global public health problem; as of February 28, 2020, it had already caused disease in $>60$ countries. After it first appeared in China, ${ }^{1}$ Thailand became the second country where COVID-19 occurred. ${ }^{2}$ Presently, COVID-19 is under surveillance in Thailand. Even after several attempts to control the disease, both imported cases and local transmissions still occur. ${ }^{3}$ Based on the knowledge, attitude, practice (KAP) theory, good knowledge is necessary for successful disease control. Here, we report the results of a questionnaire on knowledge of COVID-19 administered to medical personnel in a rural area of Thailand. The setting is the Nang Rong district, a rural region of Thailand in Buriram Province, $410 \mathrm{~km}$ from Bangkok and adjacent to Cambodia.

Briefly, a 10-question questionnaire (Table 1) was used to test the overall knowledge of 124 medical personnel (42 males and 82 females;

Author for correspondence: Dr Patthamaporn Apaijitt, E-mail: nangronpubhealth@ gmail.com

Cite this article: Apaijitt $P$ and Wiwanitkit V. (2020). Knowledge of coronavirus disease 2019 (COVID-19) by medical personnel in a rural area of Thailand. Infection Control \& Hospital Epidemiology, 41: 1243-1244, https://doi.org/10.1017/ice.2020.159
Table 1. Study Questionnaire

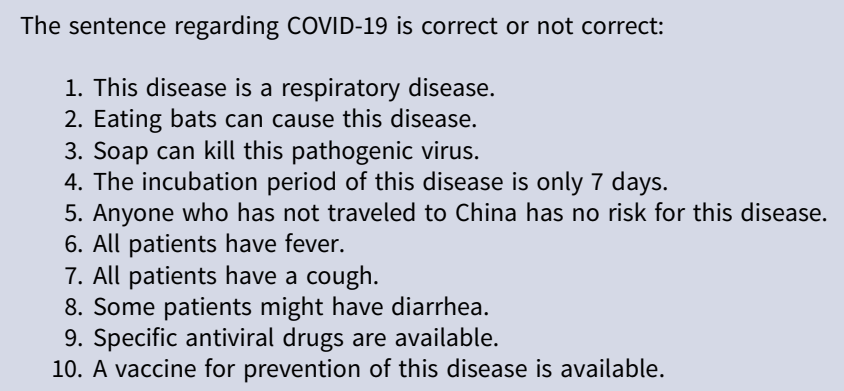

average age, $36.7 \pm 7.9$ years) working in the study area ( 5 physicians, 81 nurses, 20 nurse assistants, 12 public health workers, and 6 other medical workers). The average total knowledge score was $6.26 \pm 1.42$. We observed no association between the total knowledge score and sex or age, but there was a significant association between total knowledge score and type of medical personnel. Many medical personnel still have a low level of overall knowledge about COVID-19, despite the emergence of the disease in Thailand and after several public 